\title{
Rapid Benzylation of Cellulose in Tetra-n-butylphosphonium Hydroxide Aqueous Solution at Room Temperature
}

\section{$\operatorname{AUTHOR}(\mathrm{S})$ :}

Abe, Mitsuru; Sugimura, Kazuki; Nishiyama, Yoshiharu; Nishio, Yoshiyuki

\section{CITATION:}

Abe, Mitsuru ...[et al]. Rapid Benzylation of Cellulose in Tetra-n-butylphosphonium Hydroxide Aqueous Solution at Room Temperature. ACS Sustainable Chemistry \& Engineering 2017, 5(6): 4505-4510

\section{ISSUE DATE:}

2017-04-25

URL:

http://hdl.handle.net/2433/226163

\section{RIGHT:}

This document is the Accepted Manuscript version of a Published Work that appeared in final form in 'ACS Sustainable Chemistry and Engineering', copyright ( $\odot$ American Chemical Society after peer review and technical editing by the publisher. To access the final edited and published work see http://doi.org/10.1021/acssuschemeng.7b00492;; The fulltext file will be made open to the public on 25 April 2018 in accordance with publisher's 'Terms and Conditions for SelfArchiving'; この論文は出版社版でありません。引用の際には出版社版をご確認ご利用ください。; This is not the published version. Please cite only the published version. 


\section{Rapid Benzylation of Cellulose in Tetra- $n-$}

\section{butylphosphonium Hydroxide Aqueous Solution at}

\section{Room Temperature}

Mitsuru Abe, ${ }^{\dagger, \downarrow}$ Kazuki Sugimura, ${ }^{\dagger}$ Yoshiharu Nishiyama, ${ }^{\ddagger}$ and Yoshiyuki Nishio ${ }^{*}, \dagger$

†Division of Forest and Biomaterials Science, Graduate School of Agriculture, Kyoto University, Sakyo-ku, Kyoto 606-8502, Japan

Centre de Recherches sur les Macromolecules Vegetales (Affiliated with Joseph Fourier University of Grenoble), CNRS, B.P. 53, 38401, Grenoble Cedex 9, France

${ }^{*}$ Corresponding author. E-mail: ynishio@kais.kyoto-u.ac.jp

KEYWORDS: Cellulose, Etherification, Benzylation, Tetra- $n$-butylphosphonium hydroxide, Rapid reaction

ABSTRACT: We found a very fast benzylation of cellulose in a tetraalkyl-onium hydroxide solvent system, $47 \%$ tetra- $n$-butylphosphonium hydroxide aqueous solution. Benzyl cellulose (BC) with a degree of substitution (DS) above 2.5 was obtained within 10 min at ambient temperature $\left(20-25{ }^{\circ} \mathrm{C}\right)$ using $\sim 9$ molar equivalents of benzyl bromide to the anhydroglucose 
unit. The highly efficient benzylation proceeded in the transiently stabilized emulsion state of the reaction system, and the product precipitated out as a solid sediment in the liquid medium. At $20^{\circ} \mathrm{C}$, the benzyl DS was 1.92 after 2 min, and reached 2.40 and 2.53 after 5 and 10 min, respectively. The reaction temperature had a negative correlation with the maximum DS in the explored range of $10-50{ }^{\circ} \mathrm{C}$. No significant degradation of the cellulosic main chain was observed for highly substituted BCs (DS > 2.5). The solubility of BC in common organic solvents was also examined for products with various DSs.

\section{INTRODUCTION}

Cellulose is the most abundant natural polymer on earth and is widely available from plant sources. It can even be an attractive candidate to replace petroleum-based organic materials. An intrinsic problem of cellulose is the intractability in materialization: cellulose cannot be meltprocessed in itself and has limited industrially viable solvents. The reactivity of three hydroxyl groups in each glucose residue certainly permits a wide range of modifications of cellulose for different functionalities. ${ }^{1-4}$ However, to derivatize the molecule, the hydroxyl groups must be activated and easily accessible by the reactant; hence, proper swelling or dissolution of pristine cellulose is generally required, and the reaction often needs a significant excess of solvents or intense pretreatments, such as ball milling, to increase the amount of the amorphous phase. Thus, the total production cost of the cellulose derivatives can be relatively high despite the availability of the primary resource. ${ }^{1-4}$

Recently, Abe et al. reported that tetraalkyl-onium hydroxide aqueous (aq.) solutions dissolved cellulose at ambient temperature., ${ }^{5,6}$ Tetra- $n$-butylphosphonium hydroxide 
$\left(\left[\mathrm{P}_{4,4,4,4}\right] \mathrm{OH}\right)$ and tetra- $n$-butylammonium hydroxide aq. solutions dissolved over 15 wt $\%$ cellulose within a few minutes at $25{ }^{\circ} \mathrm{C}$, without pretreatment. In the present paper, we would like to demonstrate that a $\left[\mathrm{P}_{4,4,4,4}\right] \mathrm{OH}$ aq. solution is employable as an excellent medium for facile etherification of cellulose.

Cellulose ethers, such as alkyl cellulose, hydroxyalkyl cellulose, and carboxyalkyl cellulose, are used as auxiliaries in food, cosmetics, pharmaceuticals, adhesives, etc. ${ }^{7-14}$ (e.g., as a thickener or stabilizer for suitable rheological properties in fluid states). Among many possible etherifications, we chose benzylation as a model reaction of cellulose etherification in a $\left[\mathrm{P}_{4,4,4,4}\right] \mathrm{OH}$ aq. solution; rapid benzyl substitution is a comparatively difficult and challenging reaction in various derivatives of cellulose. ${ }^{15}$ Practically, benzyl cellulose (BC) has some potential applications that have been claimed in technical patents: $\mathrm{BC}$ can be used for hemodialysis in medical treatments ${ }^{16}$ and for commodities involving coatings, tubes, adhesives, inks, and binder compositions. ${ }^{17}$

Conventionally, cellulose etherification is done with a halogenated reagent under heterogeneous conditions using a concentrated $\mathrm{NaOH}$ aq. solution that swells cellulose fibers and simultaneously activates the hydroxyl groups of the polymer molecule. Gomberg et al. conducted benzylation of cotton and filter paper cellulose with benzyl chloride in a $\mathrm{NaOH}$ aq. solution at $100{ }^{\circ} \mathrm{C}$ and obtained BC products with benzyl degrees of substitution (DSs) of 0.43 and 1.41, respectively. ${ }^{18}$ The molar ratio of the in-fed benzyl chloride to the anhydroglucose unit (AGU) of cellulose was 8 .

Alternatively, etherification can be achieved in homogeneous cellulose solutions, often on the laboratory scale. Isogai et al. carried out benzylation of cellulose in $\mathrm{LiCl} / \mathrm{N}, \mathrm{N}$ dimethylacetamide as a reaction medium $\left(85^{\circ} \mathrm{C}\right)$ mixed with powdered $\mathrm{NaOH}$ as an activation 
agent. The addition of a large excess of benzyl chloride (45 times in mol to AGU) produced a BC with DS $=2.8 .^{19}$ They also attained a complete tri- $O$-benzylation of cellulose in aprotic polar solvent systems, $\mathrm{N}_{2} \mathrm{O}_{4} / N, N$-dimethyl sulfoxide (DMSO) and $\mathrm{SO}_{2} /$ diethylamine/DMSO, ${ }^{19,20}$ again using a high molar excess of benzyl chloride and $\mathrm{NaOH}$. A more recently discovered solvent, DMSO/tetrabutylammonium fluoride trihydrate, worked in a similar way. ${ }^{21,22}$ However, the trouble with these solvent systems is the long reaction time (commonly $>4 \mathrm{~h}$ ) at elevated temperatures $\left(>70^{\circ} \mathrm{C}\right)$. Instead of such organic solvent systems, a $\mathrm{NaOH} /$ urea aq. solution was

recently used as another cellulose solvent and homogeneous reaction medium for benzylation. ${ }^{15}$ However, lower substituted BCs (DS $=0.29-0.54)$ were solely obtained by a $4 \mathrm{~h}$ reaction at $70{ }^{\circ} \mathrm{C}$. The large volume fraction of water $(\sim 90 \%)$ is probably an obstacle to achieve higher DS because the water would compete with cellulose hydroxyls to react with the halide reagent.

In the present study, we applied a strong base, $\left[\mathrm{P}_{4,4,4,4}\right] \mathrm{OH}$ aq. solution, to the reaction medium with the aim of achieving faster and more efficient cellulose benzylation. This solvent dissolves cellulose with an appreciably lower content of water $(<50 \%)$ compared to the $\mathrm{NaOH} / \mathrm{urea}$ aq. solution and therefore is expected to be more suitable for cellulose etherification.

\section{EXPERIMENTAL SECTION}

Original Materials. A 40\% $\left[\mathrm{P}_{4,4,4,4}\right] \mathrm{OH}$ aq. solution was purchased from Sigma-Aldrich Co. LLC and was concentrated to $47 \%$ by evaporation at $30{ }^{\circ} \mathrm{C}$ under vacuum before use. $\mathrm{NaOH}$, urea, benzyl bromide (BnBr), ethanol, pyridine (dehydrated), 4-dimethylaminopyridine (DMAP), acetic anhydride $\left(\mathrm{Ac}_{2} \mathrm{O}\right)$, chloroform, toluene, tetrahydrofuran (THF), acetone, DMSO, and chloroform-d $\left(\mathrm{CDCl}_{3}\right)$ were purchased from Sigma-Aldrich Co. LLC; all were guaranteed 
reagent-grade and used as received. Microcrystalline cellulose Avicel ${ }^{\circledR} \mathrm{PH}-302$, purchased from FMC Europe N. V., Belgium, was dried under vacuum for $24 \mathrm{~h}$ at $25^{\circ} \mathrm{C}$ before use.

Synthesis of Benzyl Cellulose. The $47 \%\left[\mathrm{P}_{4,4,4,4}\right] \mathrm{OH}$ aq. solution was tentatively adopted as the benzylating reaction medium because this was the optimum concentration to dissolve cellulose. ${ }^{5,6}$ Cellulose powder $(0.09 \mathrm{~g})$ was dissolved at $3.0 \mathrm{wt} \%$ in the $\left[\mathrm{P}_{4,4,4,4}\right] \mathrm{OH}$ aq. solution (2.91 g) with gentle stirring for $30 \mathrm{~min}$ at $25^{\circ} \mathrm{C}$. $\mathrm{BnBr}$ was added dropwise to the cellulose solution, and the mixture was gently stirred under a $\mathrm{N}_{2}$ atmosphere. The addition of $\mathrm{BnBr}$ was completed within $15 \mathrm{~s}$, and the reference time of the reaction was counted from the end of the addition. In the termination of the cellulose benzylation, an excess amount of ethanol (5 mL) was poured into the reaction system to consume the unreacted $\mathrm{BnBr}$. The resulting $\mathrm{BC}$ was purified by dissolution in pyridine $(1 \mathrm{~mL})$ and reprecipitation in ethanol $(30 \mathrm{~mL})$. Finally, the purified $\mathrm{BC}$ was collected by filtration with ethanol washing and vacuum-dried at $25^{\circ} \mathrm{C}$ for $24 \mathrm{~h}$. The in-fed amount of $\mathrm{BnBr}$ was varied from 3 to 15 molar equivalents to AGU. The reaction temperature and time were controlled in the range of $10-50{ }^{\circ} \mathrm{C}$ and $2-180 \mathrm{~min}$, respectively. We usually prepared three $\mathrm{BC}$ samples for a set of variables of the BnBr:AGU ratio, reaction temperature, and time to confirm the reproducibility of the DS evaluation.

Post-acetylation of BC. Post-acetylation was conducted to dissolve $\mathrm{BC}$ in $\mathrm{CDCl}_{3}$ according to previous papers ${ }^{23,24}$ as follows: $\mathrm{BC}(0.05 \mathrm{~g})$ and DMAP $(0.025 \mathrm{~g})$ were dissolved in $5 \mathrm{~mL}$ of pyridine under a $\mathrm{N}_{2}$ atmosphere without heating. $\mathrm{Ac}_{2} \mathrm{O}(0.75 \mathrm{~mL})$ was added into the $\mathrm{BC}$ solution, and the mixture was gently stirred at $60{ }^{\circ} \mathrm{C}$ for $4 \mathrm{~h}$. Then, $30 \mathrm{~mL}$ of ethanol was added to stop the acetylation reaction. The resulting acetylated $\mathrm{BC}$ (a-BC) precipitated as a white powder, which was purified by dissolution-reprecipitation with pyridine and ethanol. Finally, the purified a-BC was dried under vacuum at $25{ }^{\circ} \mathrm{C}$ for $24 \mathrm{~h}$. 
Fourier Transform Infrared (FT-IR) Spectroscopy. An FT-IR spectrum of the original cellulose was measured using a Shimadzu IRPrestige-21 spectrometer. The cellulose was dried at $80{ }^{\circ} \mathrm{C}$ under vacuum for $24 \mathrm{~h}$ and a standard $\mathrm{KBr}$ pellet method was employed. For BC and aBC products, cast thin films were prepared from their $2 \mathrm{wt} \%$ solutions in pyridine to collect FTIR spectra, which were recorded using a Perkin-Elmer Spectrum RXI FT-IR spectrometer.

Nuclear Magnetic Resonance (NMR) Spectroscopy. $\quad$ 400-MHz ${ }^{1} \mathrm{H}$ NMR spectra were recorded for a-BCs in $\mathrm{CDCl}_{3}$ using a Bruker UltraShield $400 \mathrm{NMR}$ spectrometer. The polymer concentration was $30 \mathrm{mg} / \mathrm{mL}$. Tetramethylsilane was used as an internal standard. The temperature was $25^{\circ} \mathrm{C}$, and the number of scans was 16 .

Size Exclusion Chromatography (SEC). SEC measurements were performed for a-BCs and the starting Avicel (nitrated according to the literature ${ }^{25,26}$ ) at $30{ }^{\circ} \mathrm{C}$ using an Agilent 390-MDS system (parts: 290-LC pump injector, ProStar 510 column oven, 390-MDS refractive index detector) equipped with two Agilent PLgel $5 \mu \mathrm{m}$ MIXED-D $300 \times 7.5 \mathrm{~mm}$ columns (part No: PL1110-6504). THF eluent was used at a flow rate of $1.0 \mathrm{~mL} / \mathrm{min}$. Each sample of cellulose derivative was dissolved in THF $(5 \mathrm{mg} / \mathrm{mL})$ at $25{ }^{\circ} \mathrm{C}$. The solutions were filtered through a poly(tetrafluoro ethylene) syringe filter (pore size, $0.45 \mu \mathrm{m}$ ) before the SEC measurement.

Solubility Test. BC samples were vacuum-dried for $6 \mathrm{~h}$ at room temperature $\left(\sim 20^{\circ} \mathrm{C}\right)$ before use. The dried BC powder was added to several solvents at a concentration of $10 \mathrm{mg} / \mathrm{mL}$, and the mixtures were gently stirred for $1 \mathrm{~h}$ at $25^{\circ} \mathrm{C}$. The solubility was estimated by judging the amount of undissolved BC with the naked eye.

\section{RESULTS AND DISCUSSION}


General Aspect of Reaction and Characterization of BC Products. When BnBr was added to the initially transparent solution of cellulose $/\left[\mathrm{P}_{4,4,4,4}\right] \mathrm{OH}$ aq., the solution became turbid. Within a few minutes, white precipitates were perceived. The floating precipitates were either fluffy or sticky, depending on the quantity of the in-fed $\mathrm{BnBr}$ (stickier at $\mathrm{BnBr} / \mathrm{AGU}$ ratios >9). After $\sim 10$ min had elapsed in the reaction progress, the supernatant became clear. The yield of BC was $0.19 \mathrm{~g}(87 \%$, when calculated based on AGU using the DS data of 2.5), for example, with the following conditions: amount of starting cellulose, $0.09 \mathrm{~g}$; $\mathrm{BnBr}$ feed, 9 molar equivalents to $\mathrm{AGU}$; temperature, $25^{\circ} \mathrm{C}$; reaction time, $180 \mathrm{~min}$. When the molar ratio of BnBr:AGU was changed to 6 , the yield of $\mathrm{BC}(\mathrm{DS} \approx 1.7)$ was $0.14 \mathrm{~g}(81 \%$ in $\mathrm{AGU})$.

Figure 1 illustrates FT-IR spectra measured for BC and its acetylated form (a-BC), together with a spectrum of the original cellulose. In the BC spectrum (Fig. 1B), the aromatic bands appearing at 1497 and $1454 \mathrm{~cm}^{-1}$ provide evidence of successful etherification of cellulose with the benzyl substituent. The $\mathrm{OH}$ stretching band $\left(3250-3750 \mathrm{~cm}^{-1}\right)$, still observed for the $\mathrm{BC}$, disappeared after the post-acetylation reaction (Fig. 1C); this confirms the full substitution of the remaining hydroxyl groups. 


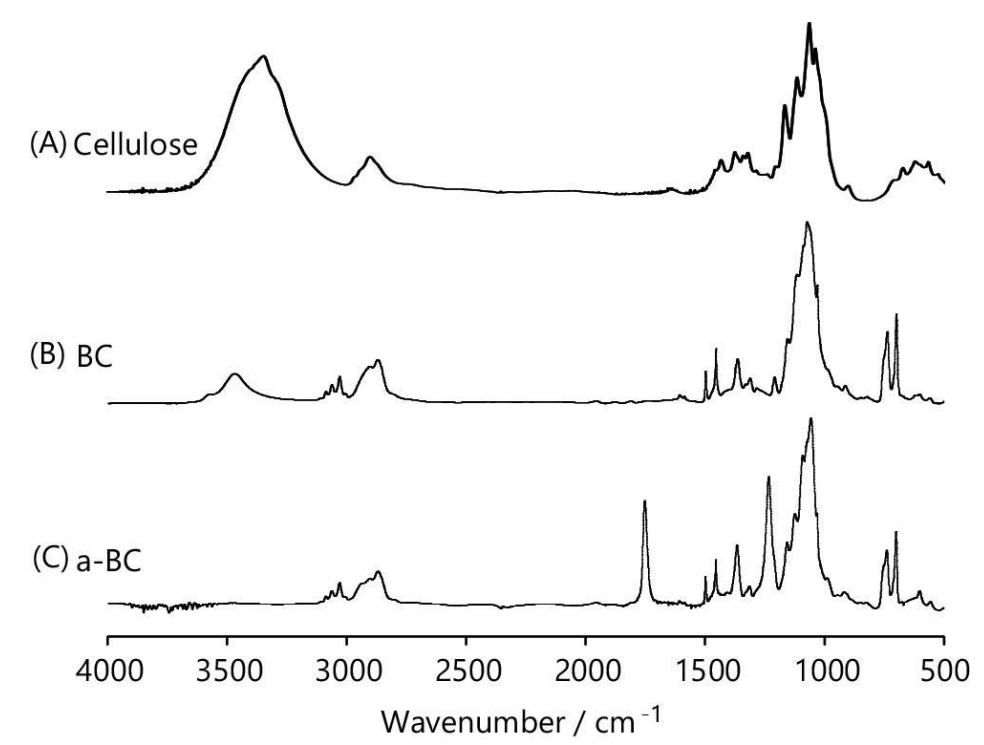

Figure 1. FT-IR spectra of (A) original cellulose (Avicel), (B) BC prepared from (A) in $\left[\mathrm{P}_{4,4,4,4}\right] \mathrm{OH}$ aq. solution with $\mathrm{BnBr}$, and (C) a-BC obtained by full acetylation of (B) with $\mathrm{Ac}_{2} \mathrm{O}$.

The benzyl DS of BC was determined using the ${ }^{1} \mathrm{H}$ NMR spectrum of the corresponding a-BC sample (see Fig. 2), according to the following equation:

$$
\text { Benzyl DS }=7 \mathbf{A} /(5 \mathbf{B}-2 \mathbf{A})
$$

where $\mathbf{A}$ is the integration from 6.5 to $8.0 \mathrm{ppm}$ (corresponding to the resonance intensity of the phenyl protons of the benzyl group) and $\mathbf{B}$ is the integration from 2.5 to $5.5 \mathrm{ppm}$ (corresponding to the total intensity of the methylene protons of the benzyl group and the seven protons in AGU). The DS reported below is an average obtained for the evaluation of multiple similarly benzylated BCs. Integral area $\mathbf{A}$ includes a signal of $\mathrm{CDCl}_{3}$, but this contribution was negligible to a tolerance $(\sim 0.05)$ of the DS quantification in the present study because BCs with high DS values (>1.5) were mainly produced. 


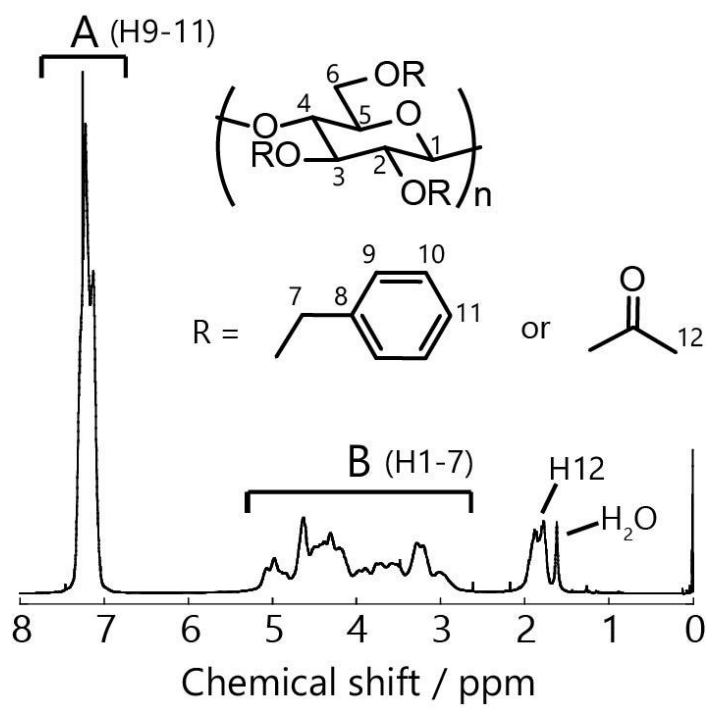

Figure 2. ${ }^{1} \mathrm{H}$ NMR spectrum of an a-BC, measured in $\mathrm{CDCl}_{3}$.

Using 9 molar equivalents of $\mathrm{BnBr}$ to $\mathrm{AGU}$ at $25^{\circ} \mathrm{C}$ for $3 \mathrm{~h}$, we obtained a $\mathrm{BC}$ product with a $\mathrm{DS}=2.49( \pm 0.06)$. We are not aware of any reports of such an efficient benzylation at ambient temperature. Thus, the $\left[\mathrm{P}_{4,4,4,4}\right] \mathrm{OH}$ aq. solution is a promising medium for etherification of cellulose. For comparison, we used a NaOH/urea aq. solution ${ }^{15}(\sim 90$ vol \% water) as a reaction medium for cellulose benzylation. Under the same conditions $\left(\mathrm{BnBr}: \mathrm{AGU}=9: 1,25^{\circ} \mathrm{C}\right.$, and $\left.3 \mathrm{~h}\right)$, the benzyl DS reached only 0.05 , although the molarity of the alkali $(\mathrm{NaOH})$ in the solution was similar to that in the $\left[\mathrm{P}_{4,4,4,4}\right] \mathrm{OH}$ aq. solution. The reagent $\mathrm{BnBr}$ remained as a macroscopic liquid phase in the reaction system due to the immiscibility of the $\mathrm{NaOH} /$ urea solvent with $\mathrm{BnBr}$, resulting in such a low efficiency for the benzylation. In contrast, tetraalkylphosphonium has both a hydrophilic and a hydrophobic moiety, i.e., it is of amphiphilic character. Therefore the cellulose $/\left[\mathrm{P}_{4,4,4,4}\right] \mathrm{OH}$ aq. solution assumed an emulsive state immediately after the initiation of benzyl substitution by $\mathrm{BnBr}$ addition, whereupon further benzylation would have rapidly proceeded in the dispersed microspheres (see Fig. 6). 
A SEC result for an a-BC (benzyl DS $=2.49$ ) (Fig. 3B) was compared to that for a nitrated cellulose (NC) prepared from the original Avicel (Fig. 3A) to examine the potential depolymerization during the benzylation reaction. The weight-average molar mass and polydispersity of the NC were ca. $9.6 \times 10^{4}$ and 3.1, respectively, when calculated based on monodisperse polystyrene. The corresponding data for the a-BC were ca. $9.2 \times 10^{4}$ and 2.5. In the SEC curve of the a-BC sample, a somewhat noticeable shoulder appeared at $\sim 14$ min, which might be due to a small amount of degradation product. However, the overall elution profile was quite similar to that of the NC sample. Therefore, we can conclude that no significant depolymerization occurred in the present benzylation process. The ambient reaction temperature $\left(25^{\circ} \mathrm{C}\right.$ for $\mathrm{BC}$ with $\left.\mathrm{DS}=2.49\right)$ might prevent degradation of the polymer chain.

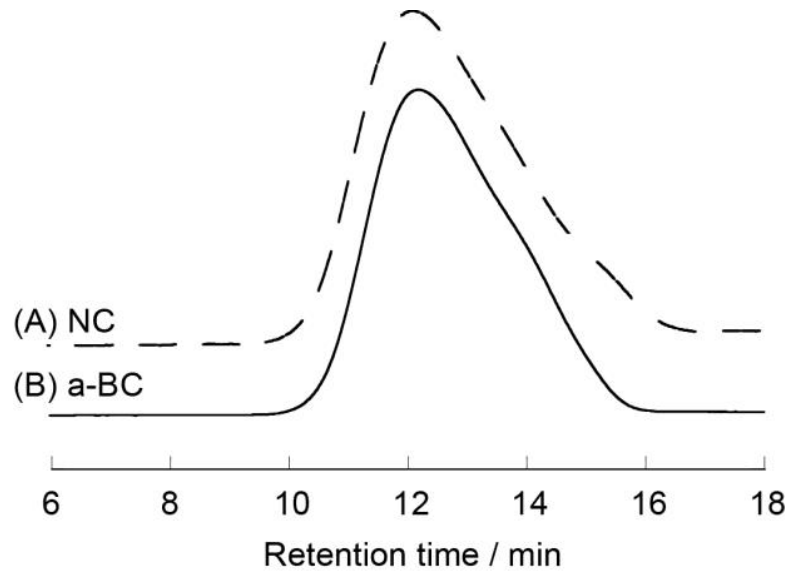

Figure 3. SEC curve of (A) nitrated Avicel (starting cellulose) (NC) and (B) BC synthesized in $\left[\mathrm{P}_{4,4,4,4}\right] \mathrm{OH}$ aq. solution with $\mathrm{BnBr}\left(25^{\circ} \mathrm{C}, 3 \mathrm{~h}\right)$, then post-acetylated (a-BC).

Effect of In-Feed Amount of BnBr. Under fixed conditions of the reaction temperature $\left(25^{\circ} \mathrm{C}\right)$ and time $(3 \mathrm{~h})$, the DS value increased linearly with the added $\mathrm{BnBr}$ amount within a range of $0-9$ in the molar ratio to AGU; e.g., $\mathrm{DS}=0.68( \pm 0.01)$ and $2.49( \pm 0.06)$ for $\mathrm{BnBr}$ :AGU 
$=3$ and 9, respectively (Fig. 4). However, a further increase of the molar ratio from 9 to 15 was essentially ineffective in raising the maximum DS; the reaction systems had transformed to a liquid-solid (sediment) bi-phasic one after more than 10 min without retaining the respective emulsion states (see below).

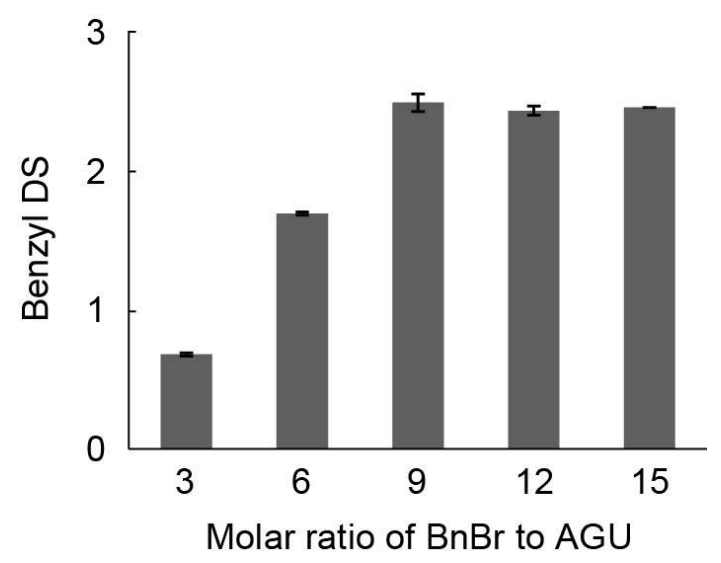

Figure 4. Benzyl DS of $\mathrm{BC}$ synthesized in $\left[\mathrm{P}_{4,4,4,4}\right] \mathrm{OH}$ aq. solution with $3 \mathrm{~h}$ stirring at $25^{\circ} \mathrm{C}$, showing the dependence on the molar ratio of $\mathrm{BnBr}$ to $\mathrm{AGU}$.

Effects of Reaction Temperature and Time. At a constant BnBr:AGU = 9:1 in-feed, the reaction temperature had a negative correlation with the benzyl DS (Fig. 5a). The highest DS, $2.69( \pm 0.04)$, was observed at $10{ }^{\circ} \mathrm{C}$. The DS value progressively decreased with increasing temperature. We currently have two hypotheses to explain the temperature dependence: (1) The increased mobility of the hydrophobic $n$-butyl chains of the $\left[\mathrm{P}_{4,4,4,4}\right]$ component at elevated temperature would reduce the surface activity to disperse the microspheres of partially benzylated cellulose. Therefore, at higher temperatures, the BC polymers would flocculate and agglomerate into a compact solid sediment at a relatively earlier stage of the benzylation 
progress. (2) The selectivity of the reaction of $\mathrm{BnBr}$ might be reduced at higher temperatures. In the present benzylation process, the bi-products, benzyl alcohol and dibenzyl ether, are formed by a side reaction of $\mathrm{BnBr}$ with water (see Supporting Information, Fig. S1). As generally recognized, the hydroxyl groups in polysaccharides have a weakly acidic nature. ${ }^{27}$ Therefore, $\mathrm{BnBr}$ preferentially reacts with the cellulose hydroxyl groups. However, the selectivity might be lowered as the temperature increases, resulting in unproductive consumption of $\mathrm{BnBr}$ by hydrolysis. Below $10{ }^{\circ} \mathrm{C}$, the cellulose $/\left[\mathrm{P}_{4,4,4,4}\right] \mathrm{OH}$ aq. solution was frozen and the benzylation was virtually unsuccessful. 

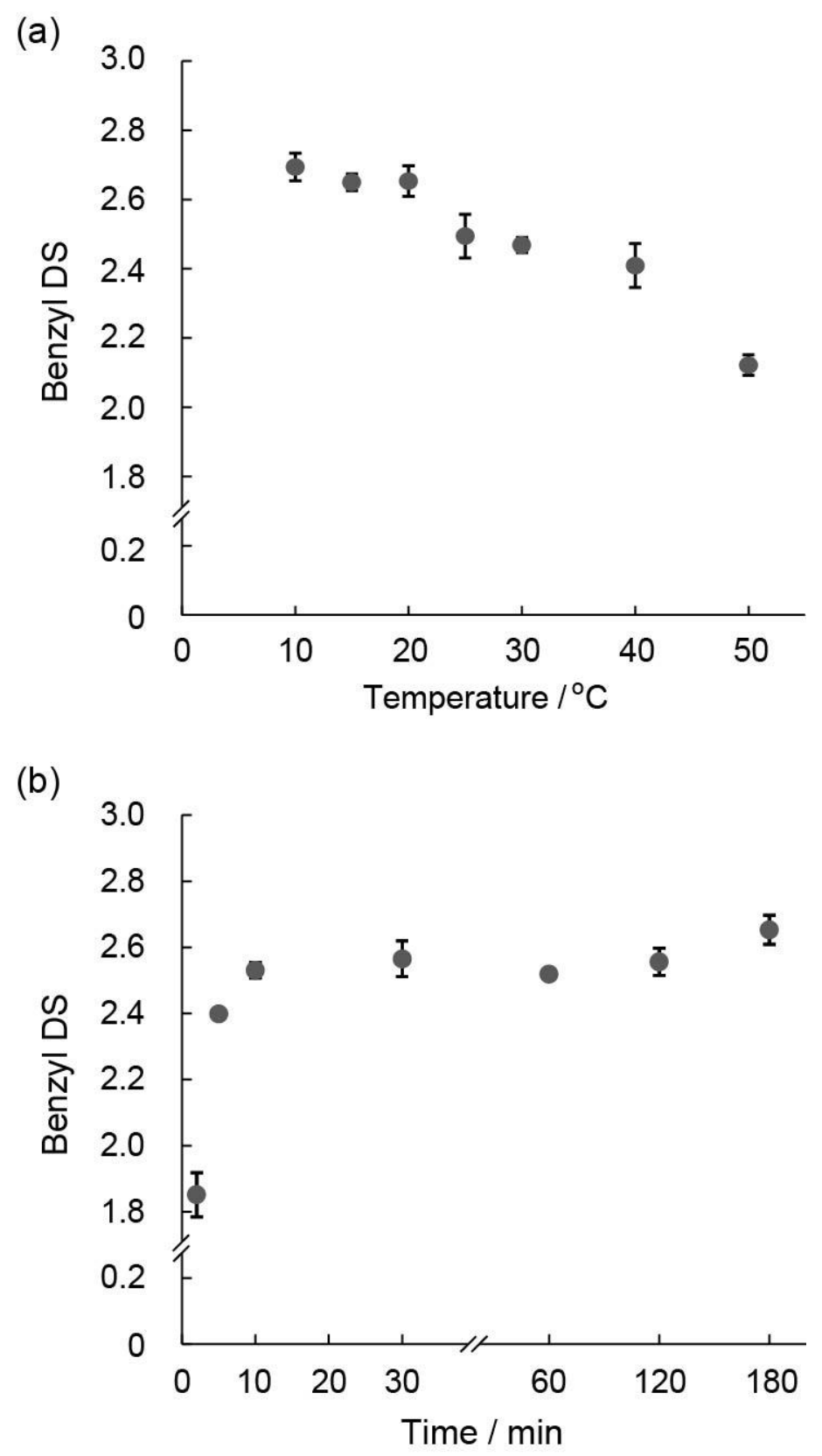

Figure 5. Benzyl DS of $B C$ synthesized in $\left[\mathrm{P}_{4,4,4,4}\right] \mathrm{OH}$ aq. solution with a molar ratio of $\mathrm{BnBr}: \mathrm{AGU}=9: 1$ in feed: (a) the dependence on the reaction temperature with $3 \mathrm{~h}$ stirring, and (b) the dependence on the reaction time at $20{ }^{\circ} \mathrm{C}$. 
Figure $5 \mathrm{~b}$ shows the time dependence of the benzyl DS of the $\mathrm{BC}$ products obtained at $20{ }^{\circ} \mathrm{C}$ in a fixed ratio of $\mathrm{BnBr}: \mathrm{AGU}=9: 1$. The $\mathrm{DS}$ was $1.92( \pm 0.04)$ within 2 min after completing the BnBr addition, and it reached $2.40( \pm 0.01)$ and $2.53( \pm 0.02)$ at 5 and $10 \mathrm{~min}$, respectively. This is a very fast reaction compared to the conventional benzylation protocols that require stirring for several hours at an elevated temperature to achieve a DS value $>2 .{ }^{19-22}$ In the present system, however, further prolonged reaction up to $3 \mathrm{~h}$ had little impact on the DS growth. Therefore it follows that the cellulose benzylation substantially finished within $10 \mathrm{~min}$ in the $\left[\mathrm{P}_{4,4,4,4}\right] \mathrm{OH}$ aq. solution.

Eventually, the highest DS attained in this reaction system by varying the temperature, time, and $\mathrm{BnBr}$ in-feed amount was $2.69( \pm 0.04)$. The saturation of the benzyl substitution may be ascribed to the essentially poor compatibility of the product with the aqueous solvent; roughly, in a mild ambient condition $\left(20-25^{\circ} \mathrm{C}\right)$, BCs with DS $>2.4$ precipitate from the emulsive reaction medium so as to form a compact sedimentation.

Model Scheme of Cellulose Benzylation in $\left[\mathbf{P}_{\mathbf{4}, \mathbf{4 , 4}, \mathbf{4}}\right] \mathrm{OH}$ aq. Solution. Using illustrations depicted in Figure 6, we summarize a possible scheme of the present benzylation as follows: As soon as the $\mathrm{BnBr}$ reagent is added into the cellulose $/\left[\mathrm{P}_{4,4,4,4}\right] \mathrm{OH}$ aq. solution, the droplets are finely dispersed because of the good lyophilic nature of the cellulose solvent. Consecutively, the $\mathrm{BnBr}$ reagent readily migrates to attack cellulose hydroxyls activated as alkoxide ions by the phosphonium cation; then, the benzylation reaction starts (Fig. 6a). Within the first minute of the reaction, the lightly benzylated cellulose molecules become hydrophobic to some extent and the initial $\mathrm{BC}$ products huddle together to form a number of microspheres in the $\left[\mathrm{P}_{4,4,4,4}\right] \mathrm{OH}$ aq. 
medium, whereupon the tetra- $n$-butylphosphonium component functions as a surfactant (Fig. 6b). The benzylating $\mathrm{BnBr}$ is partly trapped in and can also diffuse into the lipophilic BC micelles, and hence further benzylation proceeds with fast reaction kinetics in the confined space. However, the ascent of benzyl DS (e.g., approaching 2.5) diminishes the compatibility of BC with the tetraalkyl-onium hydroxide aq. solution, which collapses the BC spheres, followed by macroscopic separation into a solution-solid bi-phasic system (Fig. 6c). In this final stage, the cellulose benzylation no longer occurs, except for a possible local reaction in the interfacial region of the two phases, because the $\mathrm{BnBr}$ liquid hardly penetrates into the aggregated $\mathrm{BC}$ sediment.

(a)
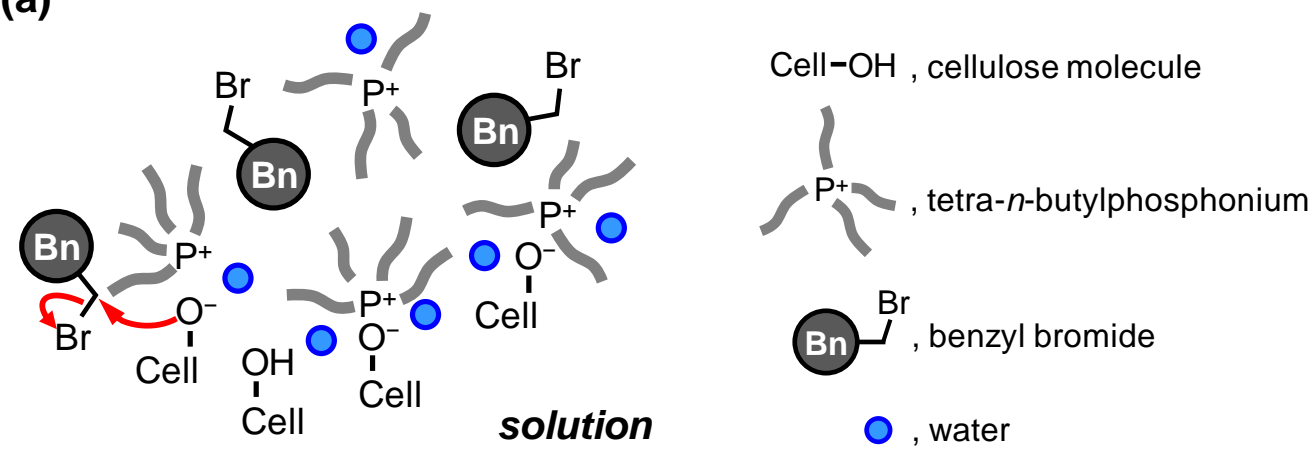

(b)

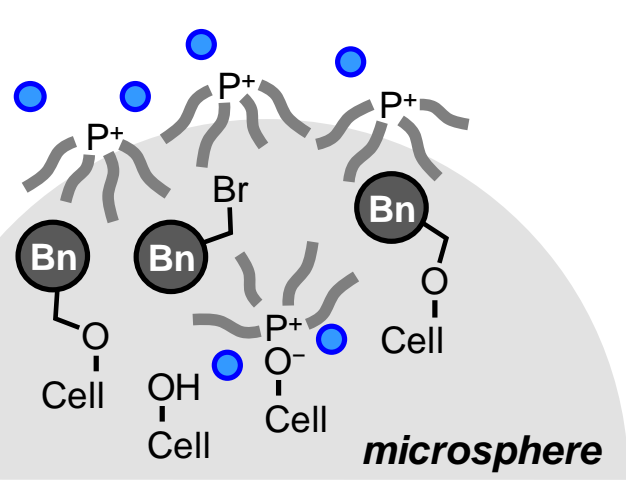

(c)

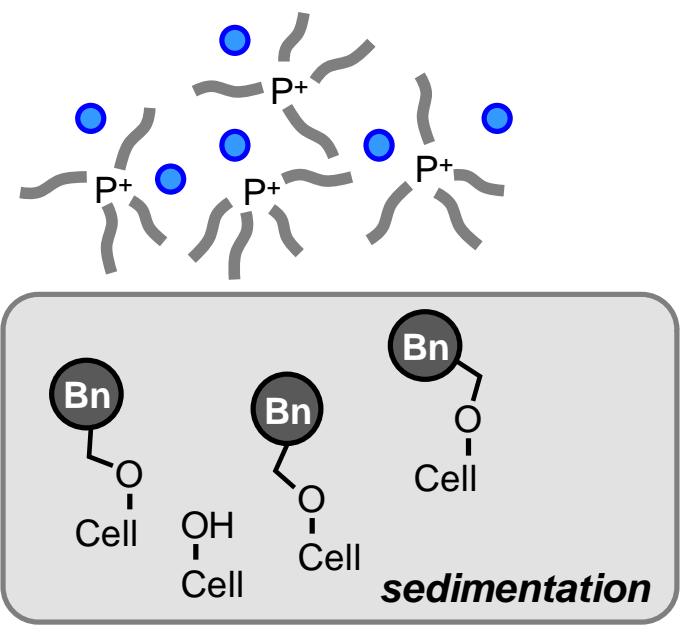


Figure 6. Model scheme of the benzylation of cellulose in $\left[\mathrm{P}_{4,4,4,4}\right] \mathrm{OH}$ aq. solution: (a) beginning of benzylation after $\mathrm{BnBr}$ addition; (b) growth of benzylation in a temporarily stabilized micelle; (c) ending of benzylation accompanied by a solution-sediment separation.

Solubility of BC in Conventional Solvents. The solubility of the BC products in organic solvents varied depending on the attained benzyl DS, as exemplified in Table 1. BCs with relatively low DSs (e.g., BC-1 and BC-2) were only soluble in DMSO and pyridine. With an increase in the DS, BCs became soluble in chloroform and THF. Somewhat interestingly, however, the $\mathrm{BC}(\mathrm{BC}-4)$ showing the highest DS of 2.69 was not soluble in DMSO. Such a tendency in the solubility of $\mathrm{BC}$ is, in part, different from that of the previous reports: e.g., BCs of DS $<1.22$ were not soluble in any of the conventional solvents, ${ }^{21}$ and a DS value $\geq 1.7$ was necessary to solubilize BC prepared in a classical heterogeneous way. ${ }^{28}$ It may be taken by comparison that, in the present preparation, the solubility of $\mathrm{BC}$ was relatively high even at a considerably lower degree of benzylation. The difference in the degree of polymerization between the starting celluloses could be partly responsible; the previous works used cotton linter as the cellulose material, while we used a microcrystalline Avicel. The difference in the distribution patterns of the benzyl ether substituents may also influence the solubility. Further characterization of $\mathrm{BC}$ and other cellulose ethers synthesized in the $\left[\mathrm{P}_{4,4,4,4}\right] \mathrm{OH}$ aq. medium, including specification of the substitution distribution, is under way. Additionally, a preliminary thermal analysis indicated that a highly benzylated $\mathrm{BC}(\mathrm{DS}=2.5$ ) exhibited a transition associated with an anisotropic phase above $130{ }^{\circ} \mathrm{C}$ besides the glass transition $\left(T_{\mathrm{g}}=\sim 90{ }^{\circ} \mathrm{C}\right)$, while a $\mathrm{BC}$ with $\mathrm{DS}=1.7$ only showed a $T_{\mathrm{g}}$ signal at $\sim 120{ }^{\circ} \mathrm{C}$ in a temperature range below 
$200{ }^{\circ} \mathrm{C}$. In parallel with the structural characterization, detail studies on the thermal and optical properties are also now in progress.

Table 1. Solubility of BC samples having various benzyl DSs in conventional organic solvents.

\begin{tabular}{|c|c|c|c|c|c|c|c|c|c|c|}
\hline \multirow[t]{2}{*}{ No. } & \multicolumn{3}{|c|}{ Preparation condition } & \multirow{2}{*}{$\begin{array}{c}\text { Benzyl } \\
\text { DS }\end{array}$} & \multicolumn{6}{|c|}{ Solubility $^{\mathrm{b}}$ (at $10 \mathrm{mg} / \mathrm{mL}$ ) } \\
\hline & Feed $^{\mathrm{a}}$ & $\begin{array}{c}\text { Temp. } \\
\left({ }^{\circ} \mathrm{C}\right)\end{array}$ & $\begin{array}{l}\text { Time } \\
\text { (min) }\end{array}$ & & DMSO & Pyridine & Chloroform & THF & Acetone & Toluene \\
\hline BC-1 & 3 & 25 & 180 & 0.68 & $\mathrm{~S}$ & $\mathrm{~S}$ & I & I & I & I \\
\hline BC-2 & 6 & 25 & 180 & 1.70 & S & S & I & $\mathrm{P}$ & I & I \\
\hline BC-3 & 9 & 25 & 180 & 2.49 & $\mathrm{~S}$ & $\mathrm{~S}$ & $S$ & S & $\mathrm{P}$ & $\mathrm{P}$ \\
\hline BC-4 & 9 & 10 & 180 & 2.69 & I & $\mathrm{S}$ & $\mathrm{S}$ & $\mathrm{S}$ & I & $\mathrm{P}$ \\
\hline
\end{tabular}

${ }^{a}$ Molar ratio of in-fed $\mathrm{BnBr}$ to $\mathrm{AGU}$ for cellulose benzylation in $\left[\mathrm{P}_{4,4,4,4}\right] \mathrm{OH}$ aq. solution.

Notations: S, soluble; P, partially soluble; I, insoluble.

\section{CONCLUSION}

We found a new route for cellulose benzylation without the usual activation of the natural polymer with $\mathrm{NaOH}$; that is, $\mathrm{BCs}$ with $\mathrm{DSs} \geq 2.5$ were readily obtained with $\mathrm{BnBr}$ in a $\left[\mathrm{P}_{4,4,4,4}\right] \mathrm{OH}$ aq. solution as the reaction medium, within $10 \mathrm{~min}$ at room temperature $\left(20-25{ }^{\circ} \mathrm{C}\right)$ via an emulsion state. The ionic solution is expected to be applicable as a good solvent for many other etherifications of cellulose. 


\section{ASSOCIATED CONTENT}

\section{Supporting Information}

The Supporting Information is available free of charge on the ACS Publications website at DOI:

10.1021/acssuschemeng.7b00492.

${ }^{13} \mathrm{C}$ NMR spectral data of bi-products formed in the present benzylation reaction (PDF)

\section{AUTHOR INFORMATION}

\section{Corresponding Author}

*Y. Nishio. E-mail: ynishio@kais.kyoto-u.ac.jp. Phone: +81-75-753-6250. Fax: +81-75-7536300.

\section{Author Contributions}

The manuscript was written through contributions of all authors. All authors have given approval to the final version of the manuscript.

\section{Notes}

The authors declare no competing financial interest.

\section{ACKNOWLEDGEMENTS}


This work was financed by a Grant-in-Aid for Scientific Research (A) (No. 26252025 to YN) from the Japan Society for the Promotion of Science. M. A. acknowledges the financial support by a Grant-in-Aid for JSPS research fellows (No. 15 J02611) and for Young Scientist Research (B) (No. 16K18731) from the Japan Society for the Promotion of Science. The authors thank Dr. I. Otsuka for the help with the SEC measurements.

\section{REFERENCES}

(1) Edgar, K. J.; Buchanan, C. M.; Debenham, J. S.; Rundquist, P. A.; Seiler, B. D.; Shelton, M.

C.; Tindall, D. Advances in cellulose ester performance and application. Prog. Polym. Sci. 2001, $26,1605-1688$.

(2) Rustemeyer, P., Ed. Cellulose Acetates: Properties and Applications (Macromolecular Symposia); Wiley-VCH: Weinheim, 2004.

(3) Kamide, K. Cellulose and Cellulose Derivatives. Molecular Characterization and its Applications; Elsevier B.V.: Amsterdam, 2005.

(4) Sugimura, K.; Teramoto, Y.; Nishio, Y. Cellulose Acetate. In Encyclopedia of Polymeric Nanomaterials; Kobayashi, S., Müllen, K., Eds.; Springer: Berlin/Heidelberg, 2015; pp. 339-347.

(5) Abe, M.; Fukaya, Y.; Ohno, H. Fast and facile dissolution of cellulose with tetrabutylphosphonium hydroxide containing 40 wt\% water. Chem. Commun. 2012, 48, 18081810. 
(6) Abe, M.; Kuroda, K.; Ohno, H. Maintenance-Free Cellulose Solvents Based on Onium Hydroxides. ACS Sustain. Chem. Eng. 2015, 3, 1771-1776.

(7) Klemm, D.; Heublein, B.; Fink, H. -P.; Bohn, A. Cellulose: Fascinating Biopolymer and Sustainable Raw Materials. Angew. Chem. Int. Ed. 2005, 44, 3358-3393.

(8) Heinze, T.; Liebert, T. Unconventional methods in cellulose functionalization. Prog. Polym. Sci. 2001, 26, 1689-1762.

(9) Nagel, M. C. V.; Koschella, A.; Voiges, K.; Mischnick P.; Heinze, T. Homogeneous methylation of wood pulp cellulose dissolved in $\mathrm{LiOH} / \mathrm{urea} / \mathrm{H}_{2} \mathrm{O}$. Eur. Polym. J. 2010, 46, 17261735.

(10) Zhou, Q.; Zhang, L. N.; Li, M.; Wu, X. J.; Cheng, G. Z. Homogeneous hydroxyethylation of cellulose in NaOH/urea aqueous solution. Polym. Bull. 2005, 53, 243-248.

(11) Song, Y. B.; Sun, Y. X.; Zhang, X. Z.; Zhou, J. P.; Zhang, L. N. Homogeneous Quaternization of Cellulose in NaOH/Urea Aqueous Solutions as Gene Carriers. Biomacromolecules, 2008, 9, 2259-2264.

(12) Qi, H. S.; Liebert, T.; Meister, F.; Heinze, T. Homogeneous carboxymethylation of cellulose in NaOH/urea aqueous solution. React. Funct. Polym. 2009, 69, 779-784.

(13) Sarkar, N. Thermal gelation properties of methyl and hydroxypropyl methylcellulose. $J$. Appl. Polym. Sci. 1979, 24, 1073-1087.

(14) Kester, J. J.; Fennema, O. An Edible Film of Lipids and Cellulose Ethers: Barrier Properties to Moisture Vapor Transmission and Structural Evaluation. J. Food Sci. 1989, 54, 1383-1389. 
(15) Li, M. -F.; Sun, S. -N.; Xu, F.; Sun, R. -C. Cold NaOH/urea aqueous dissolved cellulose for benzylation: Synthesis and characterization. Eur. Polym. J. 2011, 47, 1817-1826.

(16) Diamantoglou, M.; Lemke, H. -D. Dialysis membrane made of polysaccharide ether. Patent US 1992/5171444, December 15, 1992.

(17) Zweigle, M. L. Purification of cellulose ether reaction product. Patent US 1980/4229572, October 21, 1980.

(18) Gomberg, M.; Buchler, C. C. BENZYL ETHELS OF CARBOHYDRATES. J. Am. Chem. Soc. 1921, 43, 1904-1911.

(19) Isogai, A.; Ishizu, A.; Nakano, J. Preparation of Tri- $O$-benzylcellulose by the Use of Nonaqueous Cellulose Solvents. J. Appl. Polym. Sci. 1984, 29, 2097-2109.

(20) Isogai, A.; Ishizu, A.; Nakano, J. Preperation of Tri- $O$-Substituted Cellulose Ethers by the Use of a Nonaqueous Cellulose Solvent. J. Appl. Polym. Sci. 1984, 29, 3873-3882.

(21) Ramos, L. A.; Frollini, E.; Koschella, A.; Heinze, T. Benzylation of cellulose in the solvent dimethylsulfoxide/tetrabutylammonium fluoride trihydrate. Cellulose 2005, 12, 607-619.

(22) Rohleder, E.; Heinze, T. Comparison of Benzyl Celluloses Synthesized in Aqueous $\mathrm{NaOH}$ and Dimethyl Sulfoxide/Tetrabutylammonium Fluoride. Macromol. Symp. 2010, 294, 107-116.

(23) Aoki, D.; Nishio, Y. Phosphorylated cellulose propionate derivatives as thermoplastic flame resistant/retardant materials: influence of regioselective phosphorylation on their thermal degradation behaviour. Cellulose, 2010, 17, 963-976. 
(24) Abe, M.; Sugimura, K.; Nishio, Y. Regioselectivity in Acetylation of Cellulose in Ionic Liquids. ChemistrySelect 2016, 1, 2474-2478.

(25) Whistler, R. L., Wolfrom, M. L., Eds. Methods in Carbohydrate Chemistry. Vol. III Cellulose; Academic Press: New York, 1963.

(26) Shibazaki, H.; Kuga, S.; Okano, T. Mercerization and acid hydrolysis of bacterial cellulose. Cellulose 1997, 4, 75-87.

(27) Saric, S. P.; Schofield, R. K. The dissociation constants of the carboxyl and hydroxyl groups in some insoluble and sol-forming polysaccharides. Proc. R. Soc. A-Math. Phys. 1946, $185,431-447$.

(28) Lorand, E. J.; Georgi, E. A. The Mechanism of Cellulose Benzylation. J. Am. Chem. Soc. 1937, 59, 1166-1170. 


\section{$\underline{\text { Graphical Abstract }}$}

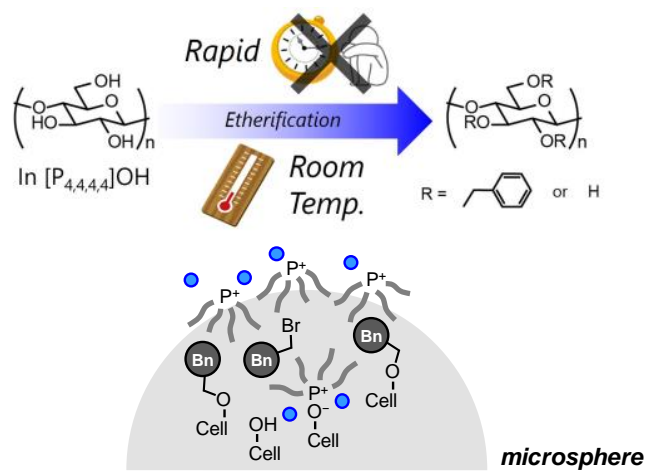

Benzyl cellulose with a degree of substitution above 2.5 was obtained with benzyl bromide in a tetra- $n$-butylphosphonium hydroxide aqueous solution, within $10 \mathrm{~min}$ at room temperature. 